\title{
Frontiers in nano-architectured carbon-metal oxide electrodes for supercapacitance energy storage: a review
}

\author{
Yiyang Liu, Zheng Zeng and Jianjun Wei* \\ The Department of Nanoscience, Joint school of Nanoscience and Nanoengineering (JSNN), University of North Carolina, Greensboro, North Carolina, USA
}

\begin{abstract}
Supercapacitor (SC) is an energy storage technology that bridges the gap between conventional capacitors and rechargeable batteries. Emerging nano-architectured carbon-metal oxide composites are promising for electrode designs for supercapacitors due to their unique strategy utilizing electrochemical double-layer capacitance (EDLC) and pseudo-capacitance together in single cell to optimize the energy storage ability and electrochemical stability. In recent years, technologies of integrating different metal oxide into single-walled/multi-walled carbon nanotubes (CNTs), graphene/reduced graphene oxide (rGO) and carbon nanofiber (CNF) and/or carbon fiber paper (CFP) have been reported with the focus of the nano-architecture electrodes. This paper provides a review of the frontiers with respect to incorporation of metal oxides into the carbon nanomaterials for capacitive energy storage improvements. Several key performance parameters in terms of specific capacitance, energy density, power density and cyclic stability along with the challenges and design trends are discussed and summarized.
\end{abstract}

\section{Introduction}

Since the fossil fuel depletion has been identified as a future challenge, the needs of efficient, renewable, sustainable energy sources are very urgent in the long term [1-3]. Energy storage systems, such as fuel cells, batteries and supercapacitors, are good power sources for electronic devices ranging from cellphones to vehicles. Among these energy storage technologies, fuel cells have the highest energy density, but their power densities are the lowest and unit size/weight usually is large. Batteries have good energy density, but their power densities are low and cycle lives are limited. Supercapacitors, also called electrochemical double layer capacitors (EDLC), are promising energy storage devices which provide higher energy density than conventional capacitors and higher power density than batteries, hence they have drawn a lot of attention due to their unique characteristics, such as high power density, fast charging/discharging rate and large cycling stability [4-6].

It is highly demanded to improve energy density and power density for supercapacitors. According to energy storage mechanism, the capacitance $\left(C_{d l}\right)$ and energy stored (E) of EDLC can be expressed by the equation: [7]

$$
\begin{aligned}
& C_{d l}=\frac{\varepsilon_{r} \varepsilon_{0} A}{d} \\
& E=\frac{1}{2} C_{d l} V^{2}=\frac{1}{2} \varepsilon_{r} \varepsilon_{0} V_{b}^{2}
\end{aligned}
$$

where $\varepsilon_{\mathrm{r}}$ is the relative dielectric constant in the double layer, $\varepsilon_{0}$ is the permittivity of free space, $A$ is the surface area of the electrode, and $\mathrm{d}$ is the thickness of the double layer. Commercially available SCs maximize the geometric term $(\mathrm{A} / \mathrm{d})$, while the electrolytes used have low $\varepsilon_{r}$, and small break down voltages $\left(V_{b}\right)$. Advanced SC concepts would focus on maximizing both geometric and materials parameters to provide energy densities greater than current Li-ion batteries, limit maintenance, and long operational life spans (e.g. 10 years) with great recharge cycles (e.g. 100,000). There is an unmet need to develop a breakthrough solution that would complement existing EDLC structures with significantly enhanced energy storage capacity.

For capacitive energy storage of high density and power that compels to rechargeable batteries, it is required that the electrode materials will withstand high electric fields and maintain a high dielectric constant. Some efforts have been taken on dielectric composites with focusing on the enhancement of the dielectric permittivity using ferroelectric metal oxides $\mathrm{Pb}(\mathrm{Zr}, \mathrm{Ti}) \mathrm{O}_{3}(\mathrm{PZT}), \mathrm{Pb}(\mathrm{Mg} 0.33 \mathrm{Nb} 0.77) \mathrm{O}_{3}-\mathrm{PbTiO}_{3}$ (PMNT), and $\mathrm{BaTiO}_{3}(\mathrm{BT})$ [8]. Some of the electroactive metal oxide, e.g. ruthenium oxide $\left(\mathrm{RuO}_{2}\right)$, manganese oxide $\left(\mathrm{MnO}_{x}\right)$, nickel oxide $(\mathrm{NiO})$, etc. offer fast and reversible redox reactions, used as supercapacitor electrodes (also called pseudocapacitors), [7,9] resulting in higher energy density capacity but some sacrifices of power density and cycle life. In order to overcome this limit and improve the performance, progresses have been made in recent years on incorporating a variety of metal oxides in carbon nanomaterials for the development of next generation supercapacitors.

Carbon nanomaterials (CNM), such as carbon nanotubes (CNTs), graphene and reduced graphene oxide (rGO), graphene nanofoam (GF) and carbon nanofibers (CNFs) possess unique size and surface dependent (e.g., morphological) properties and excellent intrinsic physical (e.g., electrical, thermal, chemical and mechanical) properties which are ideal for application in supercapacitors. The first generation CNM-based supercapacitor took advantage of the

Correspondence to: Jianjun Wei, The Department of Nanoscience, Joint school of Nanoscience and Nanoengineering (JSNN), University of North Carolina Greensboro, 2907 E, Gate City Blvd, Greensboro, NC 27401, North Carolina, USA, Tel: 1-336-285-2859, E-mail: j_wei@uncg.edu

Keywords: Energy storage, supercapacitor, carbon nanomaterials, metal oxide, dielectric.

Received: January 29, 2015; Accepted: March 04, 2016; Published: March 10, 2016 
exceptionally high surface areas, relatively high electronic conductivity to assemble an electrode for EDLC capacitor $[10,11]$. Moreover, the first generation CNM-based supercapacitors have shown improved capacitance and recycling rate capability over the traditional industrial electrode materials such as activated carbon electrodes. In order to further improve the energy density and overall performance of CNM supercapacitors, a new type of the next generation supercapacitors is emerging by utilizing unique strategies to control the nano-architecture of the dielectric metal-oxide (MO) at the surface of porous, conductive $\mathrm{CNM}$ scaffold. The CNM scaffold is used as supportive electrodes to realize ultra-high specific surface area (SSA) and to stabilize an additional active MO layer, e.g. by integrating super- or pseudocapacitance with EDLC.

In this mini-review, recent research progresses (2013-2015) in supercapacitors with the focus of nano-architectured carbon-metal oxide electrodes are reviewed based on a number of representative research publications in the past three years. Different CNM utilized for metal oxide supercapacitors are classified according to different carbon structure types, and the electrochemical energy storage performances are presented with a summary table of recently reported results. In the last, the outlook and challenges of these strategies are briefly discussed.

\section{Carbon nanomaterials-metal oxide for the next generation supercapacitors}

As abovementioned, carbon nanomaterials (CNM), e.g. CNTs, rGOs, intrinsically own high electrical conductivity, high charge transfer capability, large SSA mesoporosity, and high electrolyte accessibility, which make them attractive using as electrode materials. Since CNT [12] and graphene [13] were introduced to the applications of supercapacitor, tremendous progress has been made in the period of 1999-2012 including, but not limited to, zero-dimensional carbon onions, [14] one-dimensional highly densely packed single-walled carbon nanotubes (SWNT) [15] and two-dimensional activated graphene based supercapacitor [16]. In 2006, J. Chmiola et al. [17] found that SSA, pore size distribution (PSD) and pore shape are key factors of a high performance EDLC supercapacitor. Lots of efforts have been made after that, e.g. $\mathrm{KOH}$ thermal activation, [18-21] microwave activation, [16] to increase SSA and control PSD. These pioneer efforts have shown the advances in increasing surface area and energy storage performance. However, the activation treatment may undermine the stability of CNM, and the effective surface area is limited by the theoretical value [22]. Most of the reported EDLC capacitors have a specific capacitance around 50-300 F/g [23,24]. In contrast, carbon nanomaterials-metal oxide-based supercapacitors (CNMO-SC), notably the next generation supercapacitors, are promising candidates which may produce ultrahigh energy storage capacity $(>1000 \mathrm{~F} / \mathrm{g})$ and battery comparable energy density, while at relatively low cost $[25,26]$. Thus, a number of recent CNMO-SC studies categorized by the type of carbon nanomaterials are reviewed and discussed below.

\section{Carbon nanotubes-metal oxide based supercapacitors}

CNT is well-known for its outstanding electrical and mechanical properties such as high length to diameter ratio (up to 132,000,000:1) and intrinsically metallic property [27]. Its exceptional vertical growth mechanism facilitates the formation of a continuous network for perfect charge transport along the longitude direction. This mechanism can also form an excellent three-dimensional template known as "CNT-forest" for depositing metal-oxide to improve the energy storage capability. Carbon nanotube-forest (CNT-F) template has been coupled with
$\mathrm{MnO}_{2},[28] \mathrm{NiO},[29] \mathrm{Co}_{3} \mathrm{O}_{4}$ [30] to form the CNMO-SCs. The CNT-F$\mathrm{MnO}_{2}$ nanocomposite was designed and prepared by electrodepositing $\mathrm{MnO}_{2}$ onto plasma enhanced chemical vapor deposition (PECVD) grown CNT-F. A comparison between the cyclic voltammograms (CV) of potentiostatic-deposited $\mathrm{MnO}_{2}$ on CNT-F, galvanostatic-deposited $\mathrm{MnO}_{2}$ on CNT-F and bare CNT-F was performed and reported [28]. The $\mathrm{CV}$ of potentiostatic-deposited $\mathrm{MnO}_{2}$ on $\mathrm{CNF}$ has a better rectangular shape comparing to potentiostatic $\mathrm{MnO}_{2}$ without clear redox peaks at different scan rates $(10 \mathrm{mV} / \mathrm{s}-150 \mathrm{mV} / \mathrm{s})$. A huge increase of $\mathrm{CV}$ of galvanostatic-deposited $\mathrm{MnO}_{2}$ on CNT-F comparing to pure CNT-F was observed which is similar to CNT-F-NiO composite. In another study, CNT-F was firstly grown on a silicon substrate using a film of Fe/ $\mathrm{Al} / \mathrm{Mo}$ as both catalyst materials and current collecting layer, followed with an electrodeposition which insert nickel nanoparticles into the $3 \mathrm{D}$ structure to improve the pseudocapacitance [29]. The CNT-F-NiO nanocomposite delivers a 5.7 times higher capacitance comparing to pure CNT-F grown by chemical vapor deposition (CVD). There's no apparent current amplitude degradation after 100 cycles and only 5.8\% capacitance drop after 10000 cyclic voltammetry tests, which indicates a good stability of the electrode.

Similar CVD technique was used to grow CNT-F on silicon wafer for the $\mathrm{CNF}-\mathrm{Co}_{3} \mathrm{O}_{4}$ hybrid 3D architecture [30]. $\mathrm{ZnO}$ and $\mathrm{MnO}_{2}$ were also introduced to the CNT-F by using a microwave-assisted chemical technique as comparisons (Figure 1). The CNT-F/ $\mathrm{Co}_{3} \mathrm{O}_{4}$ composite exhibited the best performance with an areal capacitance of $30.84 \mathrm{mF} /$ $\mathrm{cm}^{2}$, a specific capacitance of $123.94 \mathrm{~F} / \mathrm{g}$, and a coulombic efficiency of about $87-92 \%$ over 1000 charge/discharge cycles. It shows that elastocapillary condensation and bending were useful tools for nanoarchitecture alternation.

In addition to CNT-F, CNT individual tubes were also coated with $\mathrm{MnO}_{2}$ [31-33] for supercapacitor electrodes. For an example, Good capacitance around 150-250 F/g and areal capacitance of $4.9 \mathrm{~F} / \mathrm{cm}^{3}$ were demonstrated of a $\mathrm{CNT} / \mathrm{MoO}_{3}$ electrode by wet chemical deposition and electrodeposition [33]. Another interesting study using nylon fiber based CNT- $\mathrm{MnO}_{2}$ electrode assembly has been reported by Choi et al. [34] via electrochemical deposition. It presented a less than $15 \%$ decrease in capacitance when reversibly stretched by $150 \%$, suggesting high flexibility as a stretchable, wearable electrode for supercapacitor applications.

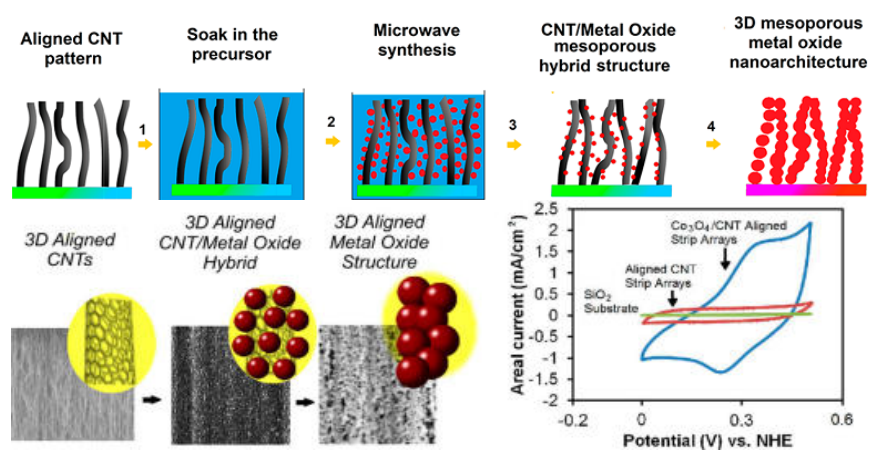

Figure 1. (Top panel) Schematic representation of the experimental steps showing the fabrication of 3D mesoporous hybrid CNT/oxide architectures and 3D mesoporous metal oxide structures; (b) (Lower panel) Scanning electron microscopy (SEM) images of 3D aligned CNTs, metal oxide hybrid electrodes, and representative cyclic voltammograms [30]. 


\section{Graphene/reduced graphene oxide-metal oxide based supercapacitors}

Graphene is two-dimensional (2D) carbon structure composed of honeycomb-shaped crystal lattice. It is the thinnest known material in the world and possesses a theoretical specific surface area of $2620 \mathrm{~m}^{2} / \mathrm{g}$ as well as extreme electrical conductivity [35]. In the next generation supercapacitor application, graphene is usually utilized as the perfect current collector/support to substitute traditional conductive substrates such as $\mathrm{Al}, \mathrm{Cu}$, Indium tin oxide(ITO), etc. [36]. Several strategies have been reported using graphene coupled with $\mathrm{MnO}_{2}$, [37-39] $\mathrm{Ni}(\mathrm{OH})_{2}$, [40] $\mathrm{CoMoO}_{4}$, [41] $\mathrm{Mn}_{3} \mathrm{O}_{4}$, [42] $\mathrm{Co}_{3} \mathrm{O}_{4}$, [43] and/or $\mathrm{MoO}_{3}$ [44]. The graphene- $\mathrm{MnO}_{2}$ nanocomposites have been demonstrated by different methods. In 2013, a facial assembly of $\delta-\mathrm{MnO}_{2}$ nanosheets and reduced graphene-oxide ( $\mathrm{rGO}$ ) flakes was demonstrated to fabricate a planar supercapacitor [37]. The synergic effects of the electrostatic effects and the morphology induced interactions strengthened the integration of rGO and $\mathrm{MnO}_{2}$ nanosheets. In the same year, graphene aerogels (GA) were synthesized via sol-gel method as the template for electrodeposited $\mathrm{MnO}_{2}$ [39] The as-prepared GA possess a high specific surface area of $793 \mathrm{~m}^{2} / \mathrm{g}$ and a high pore volume of $3 \mathrm{~cm}^{3} / \mathrm{g}$. The specific capacitance is $410 \mathrm{~F} / \mathrm{g}$ and only decays $5 \%$ after 50,000 cycles. The good capacity and stability may be attributed to the structural advantages and threedimensionally network of the GA support. Graphene is used as not only a mesporous/microporous support, but also a mechanical support in a relative large unit scale $\left(\sim 2 \mathrm{~cm}^{2}\right)$ for supercapacitor applications [45]. Two novel CVD synthesis of graphene foam (GF) on nickel foam followed by hydrothermal deposition of $\mathrm{MnO}_{2}$ [38] and $\mathrm{CoMoO}_{4}$ [41] were reported to show the outstanding electrical and mechanical properties of 3D graphene foam [38,41]. The prepared graphene foam has a relatively low SSA due to the large pore size of several hundred micrometers. However the graphene acts as both the conductive and mechanical support all by itself, which means there's no need to exploit metal current collector. The overall performance of $\mathrm{GF}-\mathrm{Ni}(\mathrm{OH})$ and GF-CoMoO ${ }_{4}$ are $144 \mathrm{~F} / \mathrm{g}$ and $439.7 \mathrm{~F} / \mathrm{g}$ in specific capacitance and $44 \mathrm{~kW} / \mathrm{kg}$ and $900 \mathrm{~W} / \mathrm{kg}$ in power density [38,41] which indicate the structural and electrochemical superiority of GF for flexible, foldable and stretchable supercapacitors. Figure 2 shows a porous structure with an interconnected $3 \mathrm{D}$ scaffold of nickel which was served as a template for the growth of 3D graphene, and morphological structures. This work illustrates a method for the development of 3-D-graphene porous skeleton electrode incorporating $\mathrm{CoMoO}_{4}$ as stable electrode for supercapacitors, with excellent pseudocapacitive performance.

A few researchers reported that graphene nano-composites with $\mathrm{Mn}_{3} \mathrm{O}_{4}$ and $\mathrm{Co}_{3} \mathrm{O}_{4}$ prepared using an in-solution process [42-44]. Specifically, GO was firstly synthesized with Hummers method, then precursor solutions were mixed with GO followed with a thermal and/ or microwave-assist treatment to deposit $\mathrm{Mn}_{3} \mathrm{O}_{4} / \mathrm{Co}_{3} \mathrm{O}_{4}$ onto the $\mathrm{rGO}$ surface. Their specific capacitance reaches $344 \mathrm{~F} / \mathrm{g}$ and $712 \mathrm{~F} / \mathrm{g}$, energy density are as high as $93 \mathrm{Wh} / \mathrm{kg}, 52.84 \mathrm{Wh} / \mathrm{kg}$. Their high performance can attribute to the more densely packed structure compared to graphene foam, which provides a highly conductive network and excellent interfacial contact for electron transport during the charge/ discharge processes. Furthermore, a notable approach [46] is reported using graphene-wrapped and microwave-assisted intercalating $\mathrm{Co}_{3} \mathrm{O}_{4}$ to form a hybrid supercapacitor electrode and demonstrate $712 \mathrm{~F} / \mathrm{g}$ capacitance and decent energy density. The intercalation of cobalt oxide nanoparticle between graphene layers and external graphenewrapping provides the excellent cycling stability.
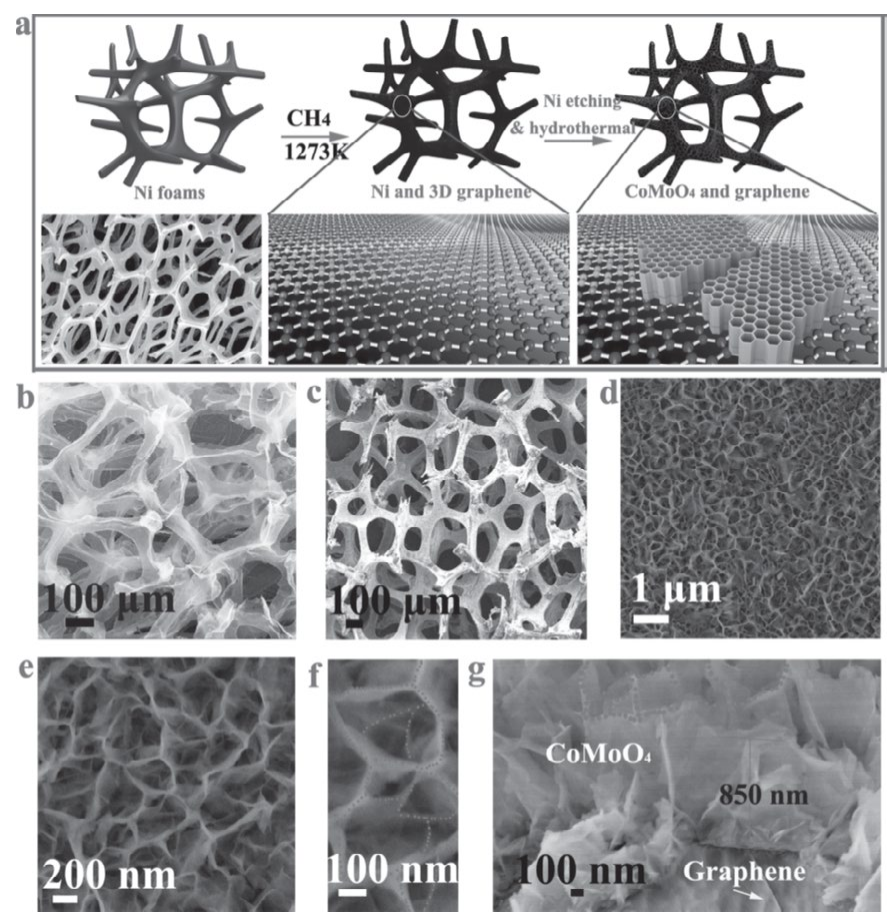

Figure 2. Growth mechanism and the morphology of honeycomb-like $\mathrm{CoMoO}_{4}-3 \mathrm{D}$ graphene hybrid electrodes. (a) the typical synthesis procedure of the graphene hybrid electrodes, (b) SEM images of (b) 3D graphene, (c-f) honeycomb-like strongly coupled $\mathrm{CoMoO}_{4}-3 \mathrm{D}$ graphene hybrid at various magnifi cation. (g) Cross-section SEM image of NHC-like $\mathrm{CoMoO}_{4}-3 \mathrm{D}$ graphene hybrid [41].

\section{Electrospun carbon nanofiber-metal oxide based super- capacitors}

Electrospun carbon nanofibers (ECNF) is well known for its large porosity, high conductivity, cheap and freestanding nature as electrode materials for EDLC applications [47,48]. Moreover, ECNF structures can also be served as scaffolds to uniformly support nanostructured metal oxide because of their reliable 3D-network structure. Carbon nanofibers (CNF) and carbon fiber paper (CFP) are essentially the same material with length of tens of micrometers and diameter range from $30 \mathrm{~nm}$ to $220 \mathrm{~nm}$. In recent years, much efforts have been focused on using ECNF synthesized by different methods as the backbone to support metal oxide pseudocapacitive materials, significantly enhancing the rate capability by shortening the distance of electron transport [49]. Activation treatment/dip-coating/ electrochemical depositions are mostly used methods in ECNF-metal oxide composites for supercapacitor applications. Activated ECNF has been coupled with $\mathrm{Co}_{3} \mathrm{O}_{4}$, [50] $\mathrm{SnO}_{2}$, [51] $\mathrm{ZnO}$ [52] and $\mathrm{V}_{2} \mathrm{O}_{5}$ [53] by incorporating different metal oxide precursors(e.g. $\mathrm{Co}(\mathrm{acac})_{2}, \mathrm{SnCl}_{2}$ $.2 \mathrm{H}_{2} \mathrm{O}, \mathrm{Zn}\left(\mathrm{O}_{2} \mathrm{CCH}_{3}\right)_{2}$, or $\mathrm{V}_{2} \mathrm{O}_{5}$ in DMF) into polyacrylonitrile (PAN) via one-step electrospinning method. The advantage of this method is the facial synthesis/processes and ultrahigh surface area $\left(>1000 \mathrm{~m}^{2} / \mathrm{g}\right)$ compared to non-activated ECNF $\left(<100 \mathrm{~m}^{2} / \mathrm{g}\right)$ [54]. The activation treatment increases the SSA but undermines the internal structure of the ECNF network, therefore the cyclic stability of these electrodes are lowered. Among these reports, the activated ECNF- $\mathrm{Co}_{3} \mathrm{O}_{4}$ electrode shows a relatively high specific capacitance of $556 \mathrm{~F} / \mathrm{g}$ with an excellent cyclic performance [50]. Figure 3 illustrates (A) the co-electrospinning setup for the preparation process of the hollow $\mathrm{Co}_{3} \mathrm{O}_{4}$ NPs-CNFs via an electrospinning and post annealing strategy and (B) images of the 
(A)

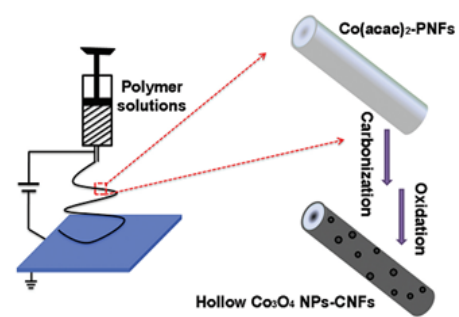

(B)

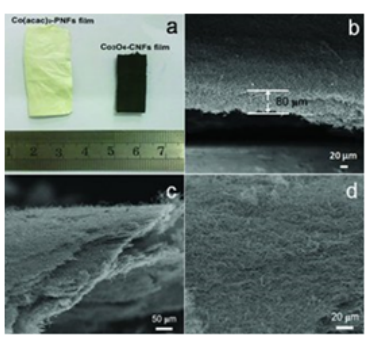

Figure 3. (A) Ideal schematic illustration for obtaining porous ECNF electrodes synthesized using co-electrospinning method with $\mathrm{H}_{2}$-reduction and post annealing strategy; and (B) the photograph of $\mathrm{Co}(\mathrm{acac})_{2}-\mathrm{PNFs}$ and $\mathrm{Co}_{3} \mathrm{O}_{4}$-ECNFs hybrid films. b,c) The side-view SEM images and d) the top-view SEM image of the $\mathrm{Co}_{3} \mathrm{O}_{4}$-ECNFs hybrid films. (cited from ref.50)
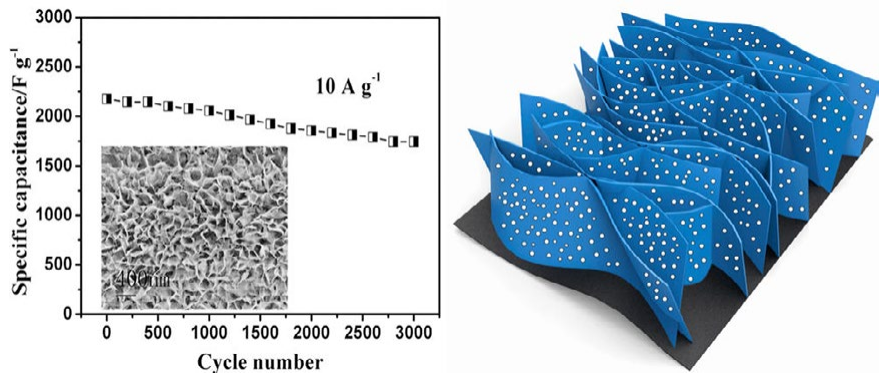

Figure 4. Ultrathin porous $\mathrm{NiCo}_{2} \mathrm{O}$ nanosheet arrays on flexible carbon fabric for high-performance supercapacitors, $\mathrm{NiCo}_{2} \mathrm{O}_{4}$ as pseudocapacitive material with higher specific capacitance is prepared as ultrathin nanosheet arrays adhered on flexible CFP as supercapacitor electrode of high performance and long cycling life [57]

\section{$\mathrm{Co}_{3} \mathrm{O}_{4}$-ECNFs hybrid film electrodes.}

Dip-coating provides a simple and low cost solution for depositing metal-oxide onto ECNF. Heat assisted $\mathrm{MnO}_{2}$ dip-coating deposition has been applied onto ECNF surface for supercapacitor application with a wide voltage range of $0-2.0 \mathrm{~V}$ [55]. The good capacitance and cyclic performance afford a convenient and efficient way to construct electrodes based on freestanding materials for energy storage system. Electrodeposition is an unique and powerful method which can quantitatively control the morphorlogy of the metal oxide active materials and easily to scale up for large amount production. A novel modified Te-nanowire template directed hydrothermal synthesis of carbon nanofiber followed with electrodeposition of ultrathin $\mathrm{NiCo}_{2} \mathrm{O}_{4}$ is reported by Zhang et al. [56]. The ECNF- $\mathrm{NiCo}_{2} \mathrm{O}_{4}$ hierarchical hybrid nanostructures have great potential as advanced electrode materials for high-performance supercapacitors.

\section{Carbon fiber paper-metal oxide based supercapacitors}

Carbon fiber paper (CFP), also known as carbon fabric or carbon cloth, is a commercial product physically similar to ECNF. It has good electric conductivity, excellent mechanical property, cheap and easy to be scaled up, yet consists of microsized carbonfibers (diameter range from 5-15 um). $\mathrm{NiCo}_{2} \mathrm{O}_{4}$ is the most popular metal oxide material coupled with CFP in the forms of $\mathrm{NiCo}_{2} \mathrm{O}_{4}$ nanorod/nanosheet arrays, [57] CFP- $\mathrm{NiCo}_{2} \mathrm{O}_{4} @ \mathrm{NiO},[58] \mathrm{CFP}-\mathrm{Ni} / \mathrm{Co}$ layered double hydroxide (LDH) [59] and CFP-Ni/Co LDH@ZnO [60]. $\mathrm{NiCo}_{2} \mathrm{O}_{4}$ precursor was electrodeposited onto CFP to form ultrathin $(10 \mathrm{~nm})$ nanosheet arrays. The interconnected structure with good conductivity of the composites delivered an astonishing high specific capacitance of $2658 \mathrm{~F} / \mathrm{g}$ and long cycling life [57]. $\mathrm{NiCo}_{2} \mathrm{O}_{4} @ \mathrm{NiO}$ core-shell hetero-nanowire on CFP has been assembled by stepwise dip-coating to fabricate the $\mathrm{NiCo}_{2} \mathrm{O}_{4} @$
NiO-CFP for a high-performance flexible all-solid-state supercapacitor [58]. $\mathrm{Ni} / \mathrm{Co} \mathrm{LDH}$ was fabricated by electrodepositing $\mathrm{Co}_{x} \mathrm{Ni}_{1-x}$ hydroxide coatings onto CFP supported hydrothermal synthesized $\mathrm{NiCo}_{2} \mathrm{O}_{\mathrm{S}}$ nanowire arrays [60]. A facile two-step hydrothermal synthesis has been applied to CFP to form a CFP-Ni/Co LDH@ZnO nanowires hybrid array for supercapacitor application [60] All three designs have shown extraordinary performance in captivity, stability and simplicity. Their high specific capacitances (1500-1900 F/g), energy density (33-45 Wh/kg) and power density (41-46 kw/kg) can be attributed to the unique 3D micrometer architecture of the CFP-Ni/ Co@Metal oxide hybrid structures.

Other than $\mathrm{NiCo}_{2} \mathrm{O}_{4}$ based composites, $\mathrm{NiCo}_{2} \mathrm{~S}_{4}[61] \mathrm{VO}_{\mathrm{x}}[62]$ and $\mathrm{NiO}$ [63] were also integrated onto CFP for high energy storage applications. $\mathrm{NiCo}_{2} \mathrm{O}_{4}$ single crystalline nanotube arrays have been grown on CFP serving as not only an excellent pseudocapacitive material but also a scaffold facilitating ion diffusion [61]. $\mathrm{VO}_{\mathrm{x}}$ and $\mathrm{NiO}$ have also been deposited onto CFP with different methods e.g. hydrothermal, dip-coating and electrodeposition [62-63]. These all show a good potential for the development of light, compact, and highperformance supercapacitors.

\section{Hybrid CNM-metal oxide based supercapacitors}

Carbon nanotube, graphene and carbon fiber are the most
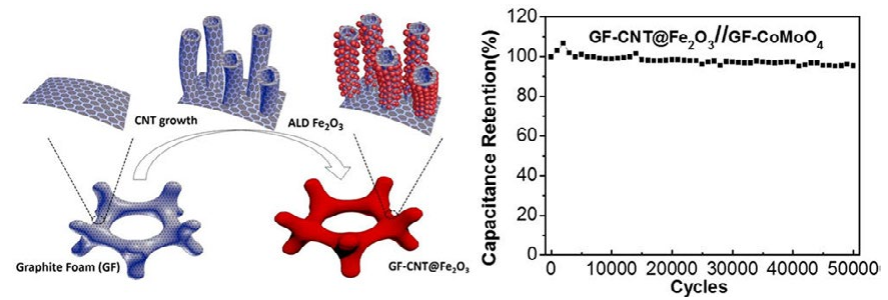

(A)
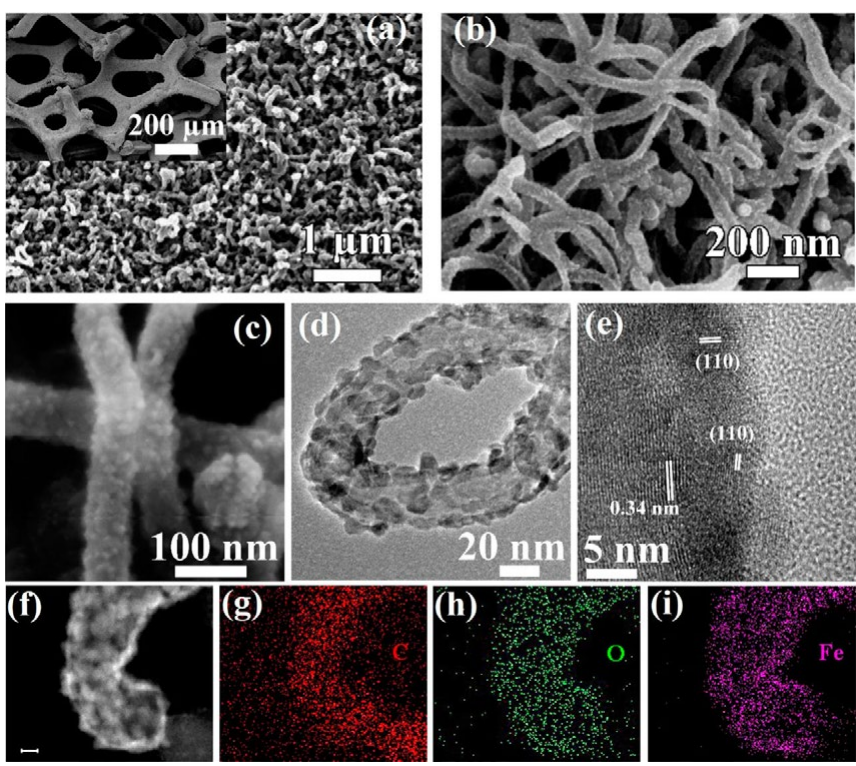

(B)

Figure 5. (A) Schematic illustration of formation of a Graphite foam@CNT- $-\mathrm{Fe}_{2} \mathrm{O}_{3}$ and extraordinary energy storage performance; (B) SEM and TEM characterization of GF CNT@Fe $\mathrm{O}_{3}$. (a c) SEM and (d e) HRTEM images of GF CNT@ $\mathrm{Fe}_{2} \mathrm{O}_{3}$. (f)HAADF STEM image of a single CNT@ $\mathrm{Fe}_{2} \mathrm{O}_{3}$ and (g-i) the corresponding STEM element mapping. The scale bar in (f) is $10 \mathrm{~nm}$ [64]. 
Table 1. A summary of representative carbon nanomaterials-metal oxide supercapacitance energy storage studies in recently years (since 2013).

\begin{tabular}{|c|c|c|c|c|c|c|c|c|}
\hline \multirow{2}{*}{$\begin{array}{l}\text { Electrode } \\
\text { materials }\end{array}$} & \multicolumn{2}{|l|}{ Metal oxide } & \multirow{2}{*}{ Capacitance $(\mathbf{F} / \mathbf{g})^{\#}$} & \multirow{2}{*}{$\begin{array}{l}\text { Energy density } \\
(\mathrm{Wh} / \mathbf{k g})^{\#}\end{array}$} & \multirow{2}{*}{$\begin{array}{l}\text { Power density } \\
(\mathbf{k W} / \mathbf{k g})^{\#}\end{array}$} & \multicolumn{2}{|c|}{ Stability } & \multirow{2}{*}{ Ref. } \\
\hline & Materials & Method & & & & cycle & $\%$ & \\
\hline \multicolumn{9}{|c|}{ CNT-forest (CNT-F) or CNT based } \\
\hline CNT-F & $\mathrm{MnO}_{2}$ & EC deposit & 642 & - & - & - & - & [28] \\
\hline CNT-F & $\mathrm{Ni} / \mathrm{NiOx}$ & EC deposit & $1.3 \mathrm{~F} / \mathrm{cm}^{3}$ & - & - & 10000 & 94.2 & [29] \\
\hline CNT-F & $\mathrm{Co}_{3} \mathrm{O}_{4}$ & microwave & 124 & & & 1000 & 92.0 & [30] \\
\hline CNT & $\mathrm{MnO}_{2}$ & wet coating & 154 & - & - & - & - & {$[31]$} \\
\hline CNT & $\mathrm{MnO}_{2}$ & EC deposit. & 247 & - & - & 2000 & 94.7 & [32] \\
\hline CNT & $\mathrm{MnO}_{2} / \mathrm{MO}_{3}$ & EC deposit & $4.9 \mathrm{~F} / \mathrm{cm}^{3}$ & 11.2 & 5.5 & 5000 & 83.0 & [33] \\
\hline CNT & $\mathrm{MnO}_{2}$ & EC deposit & $41 \mathrm{mF} / \mathrm{cm}^{2}$ & $2.6 \mathrm{mWh} / \mathrm{cm}^{2}$ & $67 \mathrm{~mW} / \mathrm{cm}^{2}$ & - & - & [34] \\
\hline \multicolumn{9}{|c|}{ Graphene foam (GF), reduced graphene oxide (rGO) based } \\
\hline GF & $\mathrm{MnO}_{2}$ & hydrothermal & 240 & 8.3 & 20 & 1000 & 90 & [38] \\
\hline GF & $\mathrm{CoMoO}_{4}$ & hydrothermal & 2741 & 37.25 & 0.9 & 10000 & 87.4 & [41] \\
\hline rGO & $\mathrm{MnO}_{2}$ & vacuum filtration & 267 & 18.6 & 12.6 & 7000 & 92.0 & [37] \\
\hline rGO & $\mathrm{MnO}_{2}$ & EC deposit & 410 & & & 50000 & 95.0 & [39] \\
\hline rGO & $\mathrm{Mn}_{3} \mathrm{O}_{4}$ & $\begin{array}{l}\text { Layer-by-layer } \\
\text { deposition }\end{array}$ & 344 & 93 & 10 & 3000 & 87.0 & [42] \\
\hline rGO & $\mathrm{Co}_{3} \mathrm{O}_{4}$ & $\begin{array}{l}\text { Precipitation } \\
\text { calcination }\end{array}$ & 636 & 30.2 & 3.75 & 1000 & 95.0 & [43] \\
\hline rGO & $\mathrm{MoO}_{2}$ & Annealing coating & 404 & 55 & 0.4 & 5000 & 80.0 & [44] \\
\hline rGO & $\mathrm{Co}_{3} \mathrm{O}_{4}$ & Microwave & 712 & 51 & 1 & 10000 & 100 & [46] \\
\hline \multicolumn{9}{|c|}{ Electrospun carbnon nanofiber (ECNF), carbon nanofiber (CNF) or carbon fiber paper (CFP) based } \\
\hline ECNF & $\mathrm{Co}_{3} \mathrm{O}_{5}$ & mix-electro-spinning & 556 & & & 2000 & 99.0 & [50] \\
\hline ECNF & $\mathrm{SnO}_{2}$ & Co-electro-spinning & 289 & 7.7 & 8 & 3000 & 97.0 & [51] \\
\hline ECNF & $\mathrm{ZnO}$ & Co-electro-spinning & 178.2 & 17.8 & 4.0 & 1000 & 75.0 & [52] \\
\hline ECNF & $\mathrm{V}_{2} \mathrm{O}_{5}$ & Co-electro-spinning & 74 & 68.5 & 20 & - & - & [53] \\
\hline $\mathrm{CNF}$ & $\mathrm{MnO}_{2}$ & Chemical growth & 56.8 & 30.6 & 0.20 & 5000 & 94.0 & [55] \\
\hline $\mathrm{CNF}$ & $\mathrm{NiCo}_{2} \mathrm{~S}_{4}$ & $\begin{array}{l}\text { Thermal-chemical } \\
\text { growth }\end{array}$ & 942 & & & 2400 & 96.4 & [56] \\
\hline CFP & $\mathrm{NiCO}_{2} \mathrm{O}_{4}$ & EC deposit & 2658 & & & 3000 & 80.0 & [57] \\
\hline CFP & $\begin{array}{l}\mathrm{NiCo}_{2} \mathrm{O}_{4} \\
\text { (a) } \mathrm{NiO}\end{array}$ & thermal co-deposit & 1500 & 33 & 41.25 & 2000 & 81.3 & [59] \\
\hline CFP & Ni-Co hydroxide & hydrothermal & 1927 & 45.6 & 46.1 & 3000 & 96.0 & [60] \\
\hline CFP & $\mathrm{NiCo}_{2} \mathrm{~S}_{4}$ & $\begin{array}{l}\text { Thermal-chemical } \\
\text { growth }\end{array}$ & $2.41 \mathrm{~F} / \mathrm{cm}$ & & & 2000 & 96.0 & [61] \\
\hline CFP & $\mathrm{VO}_{\mathrm{x}}$ & hydrothermal & 298 & $0.61 \mathrm{mWh} / \mathrm{cm}^{3}$ & $0.85 \mathrm{~W} / \mathrm{cm}^{3}$ & 10000 & 87.5 & [62] \\
\hline CFP & $\mathrm{NiO}$ & hydrothermal & $0.93 \mathrm{~F} / \mathrm{cm}$ & - & - & 10000 & 70.0 & [63] \\
\hline \multicolumn{9}{|c|}{ Two carbon nanomaterials (CNM) hybrid-based } \\
\hline $\mathrm{GF}+\mathrm{CNF}$ & $\mathrm{Fe}_{2} \mathrm{O}_{3}$ & ALD & 2555 & 74.7 & 1.4 & 50000 & 95.4 & [64] \\
\hline $\mathrm{GF}+\mathrm{CNT}$ & $\mathrm{RuO}_{2}$ & Sol-gel & 503 & 39.3 & 128 & 8100 & 106 & [65] \\
\hline $\mathrm{GF}+\mathrm{CNF}$ & $\mathrm{MnO}_{2}$ & Microwave & 948 & 53.4 & 332.5 & 1000 & 94.1 & [66] \\
\hline $\mathrm{rGO}+\mathrm{CNT}$ & $\mathrm{MnO}_{\mathrm{x}}$ & EC deposit & 1200 & 46.2 & 33.2 & 200 & 62.0 & [67] \\
\hline $\mathrm{rGO}+\mathrm{CNT}$ & $\mathrm{MnO}_{2}$ & Thermal growth & 126 & 28.33 & 5 & 2500 & 83.0 & [68] \\
\hline $\mathrm{rGO}+\mathrm{CNT}$ & $\mathrm{FeOOH}$ & hydrolysis & 267 & 30.4 & 0.24 & 1000 & 89.0 & [69] \\
\hline $\mathrm{CNF}+\mathrm{G}$ & $\mathrm{FeN}$ & ALD & 58 & 15.4 & 6.4 & 20000 & 99.0 & [70] \\
\hline $\mathrm{CNF}+\mathrm{rGO}$ & $\mathrm{Ni}(\mathrm{OH})_{2}$ & EC-deposit & 1235 & & & 500 & 80.0 & [71] \\
\hline $\mathrm{CFP}+\mathrm{rGO}$ & $\mathrm{MnO}_{2}$ & chemical & 393 & & & 2000 & 98.5 & [72] \\
\hline
\end{tabular}

\# if not specified other unit;

promising carbon materials for energy storage applications. Each of them has some superior properties, e.g. physical, morphological. Therefore, the structures that bundle multiple CNM together as hybrid materials are very attractive since they may hold their intrinsic properties and granted new characteristics prior to single CNM. Graphene foam was utilized with CNT by coupling with various metal oxides for high performance supercapacitors. Graphene foam@CNT with $\mathrm{Fe}_{2} \mathrm{O}_{3}$ [64] $\mathrm{RuO}_{2}$ [65] and $\mathrm{MnO}_{2}$ [65] were developed as novel 3D hierarchical structure. Atomic layer deposition (ALD) and modified sol-gel method were used to deposit $\mathrm{Fe}_{2} \mathrm{O}_{3}$ and $\mathrm{RuO}_{2}$ onto the graphene foam@CNT forest hybrid structures [64].

Guan et al. developed a novel iron oxide decorated graphite foamCNT forest [64]. The highest specific capacitance reaches $2555.6 \mathrm{~F} / \mathrm{g}$. The combination of CVD and ALD maximizes the conductivity and porous structure of graphene-like foam-CNT [64]. Similarly, synthesis of graphene@CNT on nickel foam followed with modified sol-gel method and dip-coating to deposit $\mathrm{RuO}_{2}$ and $\mathrm{MnO}_{2}$ onto the hybrid 
structure was demonstrated $[65,66]$. These superior designs optimize all CNM's characterizations to provide a conductive 3D network, large surface area to deposit metal oxides and react with electrolyte, cheap synthesis and processing, scaffold/support free from traditional metal current collector. $\mathrm{MnO}_{x}$ [67], $\mathrm{MnO}_{2}$ [68] FeOOH [69] coupled with graphene@CNT composites were synthesized by chemical deposition and $\mathrm{MnO}_{\mathrm{x}}$ was electrodeposited [69]. They all show good potential as supercapacitor electrodes.

Moreover, using graphene nanosheets coupled with CNT/CNF as hybrid materials for supercapacitor electrodes. $\mathrm{Fe}_{2} \mathrm{~N}$ [70] $\mathrm{Ni}(\mathrm{OH})_{2}$ [71] and $\mathrm{MnO}_{2}$ [72] were deposited onto CNF supported graphene flakes via different deposition methods, including ALD, hydrolysis/ condensation, elecrodeposition and thermal assisted chemical coating. The interconnected flexible structures exhibit good electrochemical performances with high specific capacitance and cycling performance.

\section{A summary and outlook}

This paper has reviewed recent research progress in the CNMmetal oxide composites for supercapacitor electrodes. As a summary, Table 1 reports collective results of representative research publications regarding CNM-MO supercapactors for energy storage in recent three years. Apparently, this work has no way to cover all related research published in literature. From these limited, representative results, we conclude that:

(1) Nanomaterials and nanotechnology have opened up new frontiers in materials sciences and engineering to meet the demands for high energy storage supercapacitors by offering unique enabling technology and methods;

(2) Carbon nanomaterials intrinsically have excellent conductivity, large surface area, extensive options of chemically modification, inexpensive crude materials/processes and optimal mechanical property which are promising for next generation supercapacitors.

(3) Since the metal oxide with 3D scaffold/support is the key to the high-performance next generation supercapacitors, CNT-F, graphene foam and ECNF/CNF/CFP are the highlighted CNM candidates among the all CNM substrates mentioned in previous sections. Yet their energy density regarding to whole cell is still low compared to lithium battery.

(4) Hybrid CNM-metal oxide based supercapacitors, i.e. combining two or more CNMs, have the best performance regarding the capacitance, energy/power density, suggesting the future direction of the supercapacitor electrode development. Moreover, the deposition to control the morphology of the metal oxide is one of the key factors for energy storage.

(5) The deposition methods for metal oxide and post-treatment of the CMO-MO are important for energy storage performance. The ALD $\mathrm{Fe}_{2} \mathrm{O}_{3}$ demonstrates to date the best energy density, outstanding capacitance and high stability, however cost is high. Electrochemical deposition is a facial, applicable method and low cost with a various performance from good to excellent.

However, there remain challenges guide us to overcome the barrier of insufficient electrochemical capacity of CNM-metal oxide composites, especially the energy density and long life cycle stability. Some aspects should be considered for future optimization or development of new solutions, which may significantly affect the overall performance of the supercapacitor electrodes. Those are: (1) further optimizing the geometries or dimensions in nanoscale, the interconnection of CNM, 3D networks can largely facilitate the charge transfer; (2) optimization of the metal oxide interfaces for better charge exchange and stability, and control of the morphology of CNM-metal oxide, thus high $V_{b}$; (3) requirement of standard testing methods which will make the research results under comparable conditions.

\section{Acknowledgement}

The authors acknowledge the support from JSNN at University of North Carolina at Greensboro.

\section{References}

1. Miller JR, Burke AF (2008) Electrochemical capacitors: challenges and opportunities for real-world applications. The Electrochemical Society Interface 2008, 17: 53.

2. Burke A (2000) Ultracapacitors: why, how, and where is the technology. Journal of power sources $91: 37-50$.

3. Miller JR, Simon P (2008) Materials science. Electrochemical capacitors for energy management. Science 321: 651-652. [Crossref]

4. Simon P, Gogotsi Y (2008) Materials for electrochemical capacitors. Nat Mater 7 845-854. [Crossref]

5. Largeot C, Portet C, Chmiola J, Taberna PL, Gogotsi Y, et al. (2008) Relation between the ion size and pore size for an electric double-layer capacitor. J Am Chem Soc 130: 2730-2731. [Crossref]

6. Winter M, Brodd RJ (2004) What are batteries, fuel cells, and supercapacitors? Chem Rev 104: 4245-4269. [Crossref]

7. François B, Encarnación R.-P Elzbieta F (2009) Electrical Double-Layer Capacitors and Pseudocapacitors. In Carbons for Electrochemical Energy Storage and Conversion Systems, CRC Press: 329-375.

8. Barber P Balasubramanian, S Anguchamy, Y Gong, S Wibowo, A Gao (2009) Polymer Composite and Nanocomposite Dielectric Materials for Pulse Power Energy Storage. Materials 2: 1697-1733.

9. Cottineau T Toupin, Delahaye M, Brousse T, Bélanger T (2006) Nanostructured transition metal oxides for aqueous hybrid electrochemical supercapacitors. Applied Physics A 82: 599-606.

10. Oh S, Kim K (1999) Synthesis of a new mesoporous carbon and its application to electrochemical double-layer capacitors Chemical Communications 1999: 2177-2178.

11. Zhang Y, Feng H, Wu X, Wang L, Zhang A, et al. (2009) Progress of electrochemical capacitor electrode materials: A review. International journal of hydrogen energy 34: 4889-4899.

12. Ma R, Liang J, Wei B, Zhang B, Xu C, et al. (1999) Study of electrochemical capacitors utilizing carbon nanotube electrodes. Journal of Power Sources 84: 126-129.

13. Wang Y Shi, Huang Z, Ma Y, Wang Y, Chen C, et al. (2009) Supercapacitor devices based on graphene materials. The Journal of Physical Chemistry C. 113: 13103-13107.

14. Pech D, Brunet M, Durou H, Huang P, Mochalin V, et al. (2010) Ultrahigh-power micrometre-sized supercapacitors based on onion-like carbon. Nat Nanotechnol 5: 651-654. [Crossref]

15. Futaba D, Hata N, Yamada K, Hiraoka T, Hayamizu T (2006) Shape-engineerable and highly densely packed single-walled carbon nanotubes and their application as supercapacitor electrodes. Nature materials 5: 987-994.

16. Zhu Y, Murali S, Stoller MD, Ganesh KJ, Cai W, et al. (2011) Carbon-based supercapacitors produced by activation of graphene. Science 332: 1537-1541. [Crossref]

17. Chmiola J, Yushin G, Dash R, Gogotsi Y (2006) Effect of pore size and surface area of carbide derived carbons on specific capacitance. Journal of Power Sources 158: $765-772$

18. Kierzek K, Frackowiak E, Lota G, Gryglewicz G, Machnikowski J (2004) Electrochemical capacitors based on highly porous carbons prepared by $\mathrm{KOH}$ activation. Electrochimica Acta 49: 515-523. 
19. Yoon S, Lim H, Song S, Ota Y, Qiao Y ( 2004) KOH activation of carbon nanofibers. Carbon 42: 1723-1729.

20. Wu Y, Zhang T, Zhang F, Wang Y, Ma, Y, et al. (2012) In situ synthesis of graphene/ single-walled carbon nanotube hybrid material by arc-discharge and its application in supercapacitors. Nano Energy 1: 820-827.

21. Zhang L, Zhang F, Yang X, Leng K, Huang Y, et al. (2013) High-performance supercapacitor electrode materials prepared from various pollens. Small 9: 1342-1347. [Crossref]

22. Huang J, Sumpter BG, Meunier V (2008) Theoretical model for nanoporous carbon supercapacitors. Angew Chem Int Ed Engl 47: 520-524. [Crossref]

23. Ghosh A, Lee YH (2012) Carbon-based electrochemical capacitors. Chem Sus Chem 5: 480-499. [Crossref]

24. Sharma P, Bhatti T (2010) A review on electrochemical double-layer capacitors. Energy Conversion and Management 51: 2901-2912.

25. Zhang Y, Li L, Su H, Huang W, Dong X (2010) Binary metal oxide: advanced energy storage materials in supercapacitors. Journal of Materials Chemistry A 3: 43-59.

26. Zhi M, Xiang C, Li J, Li M, Wu N (2013) Nanostructured carbon-metal oxide composite electrodes for supercapacitors: a review. Nanoscale 5: 72-88. [Crossref]

27. Terrones M (2003) Science and technology of the twenty-first century: synthesis, properties, and applications of carbon nanotubes. Annual review of materials research 33: 419-501.

28. Amade R, Jover E, Caglar B, Mutlu T, Bertran E (2011) Optimization of MnO2/ vertically aligned carbon nanotube composite for supercapacitor application. Journal of Power Sources 196: 5779-5783.

29. Jiang Y, Wang P, Zang X, Yang Y, Kozinda A, et al. (2013) Uniformly embedded meta oxide nanoparticles in vertically aligned carbon nanotube forests as pseudocapacitor electrodes for enhanced energy storage. Nano letters 13: 3524-3530.

30. Mazloumi M, Shadmehr S, Rangom Y, Nazar LF, Tang XS (2013) Fabrication of threedimensional carbon nanotube and metal oxide hybrid mesoporous architectures. ACS Nano 7: 4281-4288. [Crossref]

31. Sodtipinta J, Pon-On W, Veerasai W, Smith SM (2013) Pakawatpanurut, P. Chelating agent-and surfactant-assisted synthesis of manganese oxide/carbon nanotube composite for electrochemical capacitors. Materials Research Bulletin 48: 1204-1212.

32. Jiang Y, Ling X, Jiao Z, Li L, Ma Q, et al. (2015) Flexible of multiwalled carbon nanotubes/manganese dioxide nanoflake textiles for high-performance electrochemical capacitors. Electrochimica Acta 153: 246-253.

33. Yang P, Chen Y, Yu X, Qiang P, Wang K, et al. (2014) Reciprocal alternate deposition strategy using metal oxide/carbon nanotube for positive and negative electrodes of high-performance supercapacitors. Nano Energy 10: 108-116.

34. Choi C, Kim SH, Sim HJ, Lee JA, Choi AY, et al. (2015) Stretchable, weavable coiled carbon nanotube/MnO2/polymer fiber solid-state supercapacitors. Sci Rep 5: 9387. [Crossref]

35. Geim AK (2009) Graphene: status and prospects. Science 324: 1530-1534. [Crossref]

36. Iwakura C, Fukumoto Y, Inoue H, Ohashi S, Kobayashi M, et al. (1997) Electrochemical characterization of various metal foils as a current collector of positive electrode for rechargeable lithium batteries. Journal of power sources 68: 301-303.

37. Peng L, Peng X, Liu B, Wu C, Xie Y, et al. (2013) Ultrathin two-dimensional MnO2/ graphene hybrid nanostructures for high-performance, flexible planar supercapacitors. Nano Lett 13: 2151-2157. [Crossref]

38. Bello A, Fashedemi OO, Lekitima J N, Fabiane M, Dodoo-Arhin D, et al. (2013) High-performance symmetric electrochemical capacitor based on graphene foam and nanostructured manganese oxide. AIP Advances 3: 082118.

39. Wang CC, Chen HC, Lu SY (2014) Manganese oxide/graphene aerogel composites as an outstanding supercapacitor electrode material. Chemistry-A European Journal 20: 517-523.

40. Ji J, Zhang LL, Ji H, Li Y, Zhao X, et al. (2013) Nanoporous Ni(OH)2 thin film on 3D Ultrathin-graphite foam for asymmetric supercapacitor. ACS Nano 7: 6237-6243. [Crossref]

41. Yu X, Lu B, Xu Z (2014) Super long-life supercapacitors based on the construction of nanohoneycomb-like strongly coupled $\mathrm{CoMoO}(4)-3 \mathrm{D}$ graphene hybrid electrodes. $A d v$ Mater 26: 1044-1051. [Crossref]

42. Gund GS, Dubal D P, Patil BH, Shinde SS, Lokhande CD (2013) Enhanced activity of chemically synthesized hybrid graphene oxide/Mn 3 O 4 composite for high performance supercapacitors. Electrochimica Acta 92: 205-215.

43. Xie LJ, Wu JF, Chen CM, Zhang CM, Wan L, et al. (2013) A novel asymmetric supercapacitor with an activated carbon cathode and a reduced graphene oxide-cobalt oxide nanocomposite anode. Journal of Power Sources 242: 148-156.

44. Cao X, Zheng B, Shi W, Yang J, Fan Z, et al. (2015) Reduced Graphene OxideWrapped MoO3 Composites Prepared by Using Metal-Organic Frameworks as Precursor for All-Solid-State Flexible Supercapacitors. Advanced Materials 27: 46954701.

45. Chen Z, Ren W, Gao L, Liu B, Pei S, et al (2011) Three-dimensional flexible and conductive interconnected graphene networks grown by chemical vapour deposition. Nat Mater 10: 424-428.

46. Kumar R, Kim, HJ, Park S, Srivastava A, Oh IK (2014) Graphene-wrapped and cobalt oxide-intercalated hybrid for extremely durable super-capacitor with ultrahigh energy and power densities. Carbon 79:192-202.

47. Hou H, Reneker DH (2004) Carbon nanotubes on carbon nanofibers: a novel structure based on electrospun polymer nanofibers. Advanced Materials 16: 69-73.

48. Ramakrishna S, Fujihara K, Teo WE, Yong T, Ma Z, et al. (2006) Electrospun nanofibers: solving global issues. Materials today 9: 40-50.

49. Miao J, Miyauchi M, Simmons TJ, Dordick JS, Linhardt RJ (2010) Electrospinning of nanomaterials and applications in electronic components and devices. J Nanosci Nanotechnol 10: 5507-5519. [Crossref]

50. Zhang F, Yuan C, Zhu J, Wang J, Zhang X, et al (2013) Flexible Films Derived from Electrospun Carbon Nanofibers Incorporated with Co3O4 Hollow Nanoparticles as Self-Supported Electrodes for Electrochemical Capacitors. Advanced Functional Materials 23: 3909-3915.

51. An GH, Ahn HJ (2013) Activated porous carbon nanofibers using Sn segregation for high-performance electrochemical capacitors. Carbon 65: 87-96.

52. Kim CH, Kim BH (2015) Zinc oxide/activated carbon nanofiber composites for highperformance supercapacitor electrodes. Journal of Power Sources 274: 512-520.

53. Kim BH, Yang KS, Yang DJ (2013) Electrochemical behavior of activated carbon nanofiber-vanadium pentoxide composites for double-layer capacitors. Electrochimica Acta 109: 859-865.

54. Kim C, Yang K (2003) Electrochemical properties of carbon nanofiber web as an electrode for supercapacitor prepared by electrospinning. Applied physics letters 83 : 1216-1218.

55. Wang JG, Yang Y, Huang ZH, Kang F (2013) A high-performance asymmetric supercapacitor based on carbon and carbon-MnO 2 nanofiber electrodes. Carbon 6: 190-199.

56. Zhang G, Lou XW D (2013) Controlled growth of NiCo2O4 nanorods and ultrathin nanosheets on carbon nanofibers for high-performance supercapacitors. Scientific reports.

57. Du J, Zhou G, Zhang H, Cheng C, Ma J (2013) Ultrathin porous NiCo2O4 nanosheet arrays on flexible carbon fabric for high-performance supercapacitors. ACS applied materials \& interfaces 5: 7405-7409.

58. Yang W, Gao Z, Ma J, Zhang X, Wang J, et al. (2014) Hierarchical NiCo 2 O 4@ NiO core-shell hetero-structured nanowire arrays on carbon cloth for a high-performance flexible all-solid-state electrochemical capacitor. Journal of Materials Chemistry A 2: 1448-1457.

59. Huang L, Chen D, Ding Y, Feng S, Wang ZL, et al. (2013) Nickel-cobalt hydroxide nanosheets coated on $\mathrm{NiCo} 2 \mathrm{O} 4$ nanowires grown on carbon fiber paper for highperformance pseudocapacitors. Nano Lett 13: 3135-3139. [Crossref]

60. Shakir I, Shahid M, Rana UA, Al Nashef IM, Hussain R (2014) Nickel-Cobalt Layered Double Hydroxide Anchored Zinc Oxide Nanowires grown on Carbon Fiber Cloth for High-Performance Flexible Pseudocapacitive Energy Storage Devices. Electrochimica Acta 129: 28-32.

61. Xiao J, Wan L, Yang S, Xiao F, Wang S (2014) Design hierarchical electrodes with highly conductive NiCo2S4 nanotube arrays grown on carbon fiber paper for highperformance pseudocapacitors. Nano Lett 14: 831-838. [Crossref]

62. Lu X, Yu M, Zhai T, Wang G, Xie S, et al. (2013) High energy density asymmetric quasi-solid-state supercapacitor based on porous vanadium nitride nanowire anode. Nano Lett 13: 2628-2633. [Crossref]

63. Cheng S, Yang L, Liu Y, Lin W, Huang L, et al. (2013) Carbon fiber paper supported hybrid nanonet/nanoflower nickel oxide electrodes for high-performance pseudo- 
capacitors. Journal of Materials Chemistry A 1: 7709-7716.

64. Guan C, Liu J, Wang Y, Mao L, Fan Z, et al. (2015) Iron oxide-decorated carbon for supercapacitor anodes with ultrahigh energy density and outstanding cycling stability. ACS Nano 9: 5198-5207. [Crossref]

65. Wang W, Guo S, Lee I, Ahmed K, Zhong J, et al. (2014) Hydrous ruthenium oxide nanoparticles anchored to graphene and carbon nanotube hybrid foam for supercapacitors. Sci Rep 4: 4452. [Crossref]

66. He Y, Chen W, Zhou J, Li X, Tang P, et al. (2013) Constructed uninterrupted chargetransfer pathways in three-dimensional micro/nanointerconnected carbon-based electrodes for high energy-density ultralight flexible supercapacitors. ACS applied materials \& interfaces 6: 210-218.

67. Li SM, Wang YS, Yang SY, Liu CH, Chang KH, et al. (2013) Electrochemical deposition of nanostructured manganese oxide on hierarchically porous graphenecarbon nanotube structure for ultrahigh-performance electrochemical capacitors. Journal of power sources 225: 347-355.
68. Deng L, Hao Z, Wang J, Zhu G, Kang L, et al. (2013) Preparation and capacitance of graphene/multiwall carbon nanotubes/MnO 2 hybrid material for high-performance asymmetrical electrochemical capacitor. Electrochimica Acta 89: 191-198.

69. Long C, Jiang L, Wei T, Yan J, Fan Z (2014) High-performance asymmetric supercapacitors with lithium intercalation reaction using metal oxide-based composites as electrode materials. Journal of Materials Chemistry A 2: 16678-16686.

70. Zhu C,Yang P, Chao D, Wang X, Zhang X, et al. (2015) All Metal Nitrides Solid-State Asymmetric Supercapacitors. Adv Mater 27: 4566-4571. [Crossref]

71. Zhang LL, Xiong Z, Zhao XA (2013) composite electrode consisting of nicke hydroxide, carbon nanotubes, and reduced graphene oxide with an ultrahigh electrocapacitance. Journal of Power Sources 222: 326-332.

72. Sawangphruk M, Srimuk P, Chiochan P, Krittayavathananon A, Luanwuthi S, et al. (2013) J. High-performance supercapacitor of manganese oxide/reduced graphene oxide nanocomposite coated on flexible carbon fiber paper. Carbon 60: 109-116.

Copyright: (C2016 Liu Y. This is an open-access article distributed under the terms of the Creative Commons Attribution License, which permits unrestricted use, distribution, and reproduction in any medium, provided the original author and source are credited. 